Brit. J. industr. Med., 1957, 14, 246.

\title{
CHEMICAL AND HISTOLOGICAL POST-MORTEM STUDIES ON A WORKMAN EXPOSED FOR MANY YEARS TO CADMIUM OXIDE FUME
}

\author{
BY \\ J. C. SMITH, J. E. KENCH, and J. P. SMITH
}

From the Nuffield Department of Occupational Health and the Department of Pathology, University of Manchester

(RECEIVED FOR PUBLICATION MAY 23, 1957)

Post-mortem examinations of workers who died of cadmium poisoning after exposure to cadmium oxide fume have been reported by Baader (1951), Lane and Campbell (1954), and Bonnell (1955). Friberg (1950) and Friberg and Nyström (1952) reported similar examinations of workmen subjected to cadmium oxide dust.

As part of a study of cadmium intoxication it was important to establish the distribution of absorbed cadmium in various tissues both in persons exposed to cadmium and in others not in contact with this hazard, and to discover the structural response of the tissues to cadmium deposition. One fatal case is described below.

\section{Industrial and Medical History}

The man, J. R., died on July 28, 1956, aged 46 years. From the age of 14 years he had been employed for 19 years as a kiln setter in a brick works. He then worked as an alloy section caster in a copper-cadmium foundry (Foundry II; Smith and Kench, 1957) for nine years (1942-51) and was transferred to light work involving no further exposure to cadmium in 1951, presumably on account of chest trouble.

In 1953, following influenza, he developed pneumonia and pleurisy from which he slowly recovered and eventually, after five months' absence, returned to light work. In November, 1953, this workman was one of the subjects of the survey reported by Bonnell (1955) and is referred to in that publication as B3. He was then complaining of shortness of breath and was found to have emphysema, proteinuria, and a urinary cadmium excretion of $1,240 \mu \mathrm{g}$. a day. He remained at work until the onset of acute bronchitis and bronchopneumonia a week before death. Necropsy was performed 48 hours after death.

\section{Necropsy Report}

The patient was of very slender build but showed no external evidence of disease. On opening the chest, both lungs were seen to be voluminous, extending over the mid-line and over the anterior surface of the pericardium. The degree of anthracosis was no more than is usual in town dwellers.

The left pleural cavity contained no excess of fluid but there were a few scattered old fibrous adhesions. On section the left lung ( 350 g.) showed a fairly coarse emphysema (Fig. 1) with spaces up to $1 \mathrm{~cm}$. across, diffuse throughout all the lobes, extending to the pleural surfaces where, particularly at the apex, bullae were present. The largest bulla was about $3.0 \times 2.0 \mathrm{~cm}$. in cross section.

The right pleural cavity was almost completely obliterated by dense old adhesions between which the pleura showed some recent fibrinous exudate and the pleural cavity contained a slight excess of turbid fluid. The borders of the right lung $(2,200 \mathrm{~g}$.) were rounded but no gross emphysematous bullae presented at the surface. The cut surfaces of all lobes of the right lung (Fig. 2) showed a widespread coarse emphysema with cavities up to $8 \mathrm{~mm}$. diameter, the largest being in the upper lobe. The lung was heavy and consolidated due to the presence of a greenish-yellow coagulated fluid in many of the cavities particularly in the middle and lower lobes. No pus could be expressed from the finer bronchial tree. There was a moderate amount of tenacious mucus in the right main bronchus: the left main bronchus was clear. There was no sign of fibrosis or tuberculosis, the hilar lymph nodes were normal, and there was no atheroma in the pulmonary arteries.

The pericardial cavity contained a slight excess of yellow fluid and the parietal pericardium adherent to the right lung was covered by a light fibrinous exudate. There were a few fibrinous flecks over the right ventricle. The heart $(285 \mathrm{~g}$.) showed no muscular hypertrophy and the valves were normal. There was very little atheroma in the coronary arteries and aorta. The kidneys (right, $85 \mathrm{~g}$., left, $125 \mathrm{~g}$.) had smooth subcapsular surfaces and the 


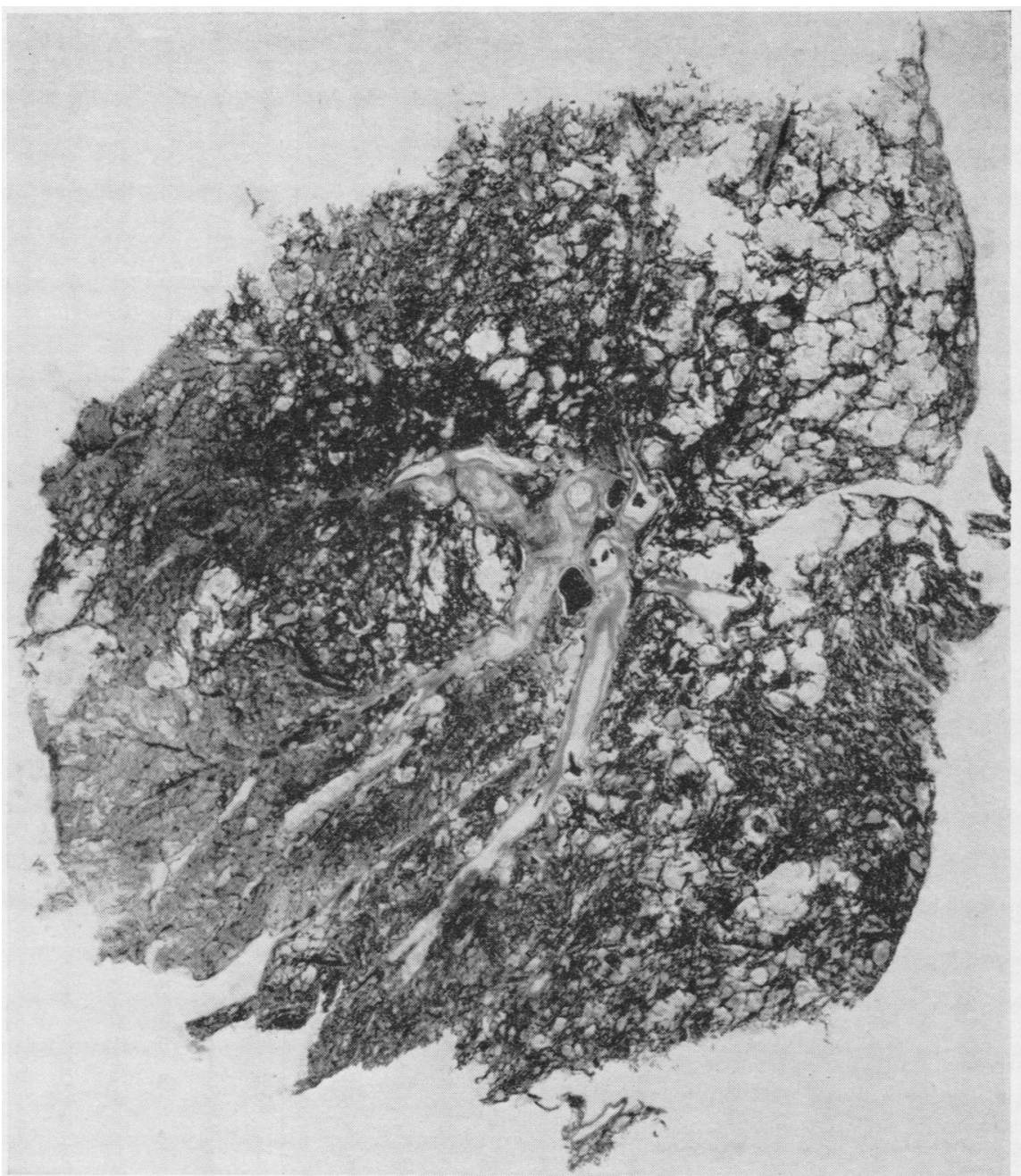

Fig. 1.-Whole section of left lung showing severe widespread emphysema.

cut surfaces showed normal cortico-medullary relationships. The pelves, ureters, bladder, prostate, seminal vesicles, and testes were normal. Other abdominal viscera, brain and meninges and the endocrine glands were normal. Fatty marrow occupied the midshaft of the femur.

Histology.-Both lungs show widespread severe emphysema. In the right lung there is a fibrinopurulent exudate in the alveolar spaces and in the lumina of the bronchi. The bronchial walls show a severe acute bronchitis in the right lung and a mild patchy acute bronchitis in the left lung. There is a notable absence of chronic inflammatory cells or of fibrosis in the bronchial walls such as would indicate a chronic bronchitis. The elastica of the residual lung tissue and the pulmonary vessels are normal.

In the kidney cortex, the glomeruli and tubules are normal. A few minor foci of atrophy and interstitial fibrosis secondary to a moderate degree of hyaline arteriolosclerosis are seen. The larger vessels are normal. There are occasional hyaline casts in collecting tubules. The renal pelvis is normal but in the submucosa of the ureters and bladder are small focal collections of macrophages and plasma cells. The seminal vesicles, prostate, and vas are normal; the testes show a little depression of spermatogenesis.

The liver is congested; the oesophagus shows a calcifying leiomyoma in its wall; no significant abnormalities are seen in the brain, heart, pancreas, 


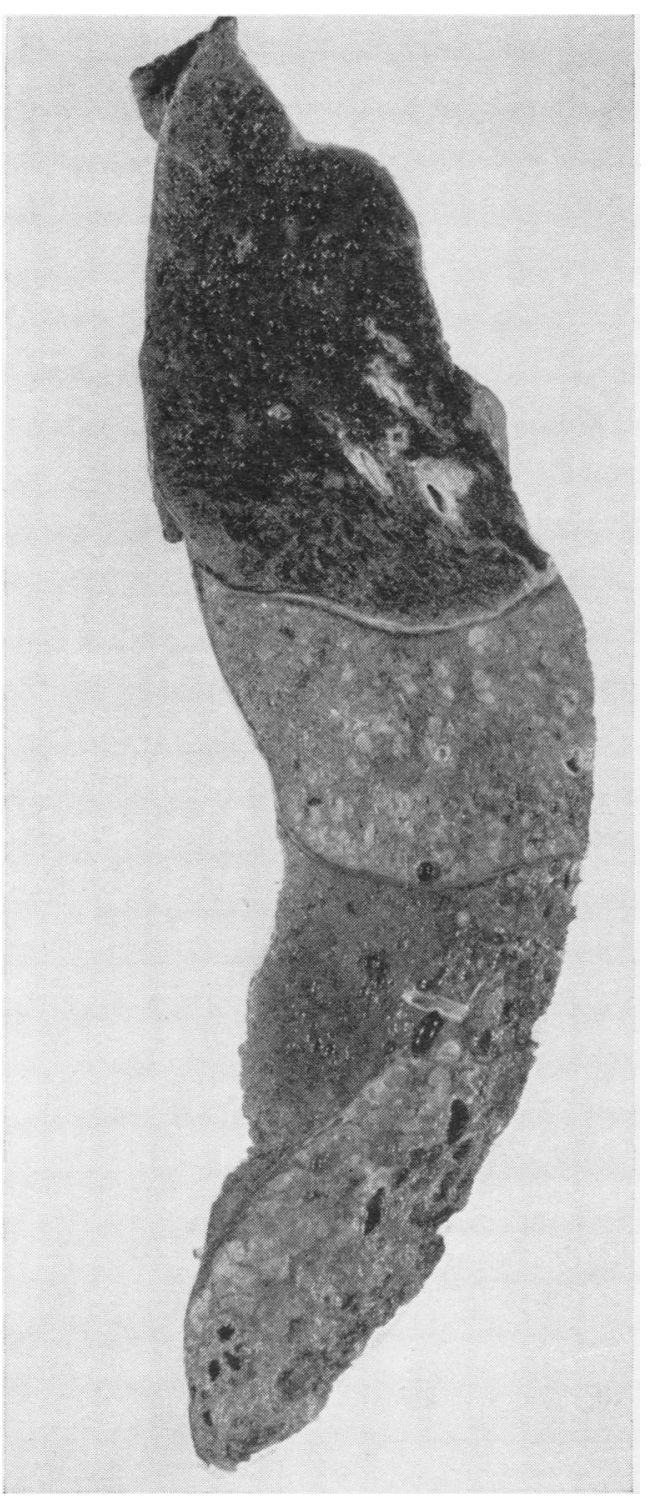

Fig. 2.-Cut surface of right lung showing severe emphysema and pneumonic consolidation.

spleen, gastro-intestinal tract, trachea, bone marrow, pituitary, thyroid, and adrenals.

Slight fatty changes in the liver and kidney are present and are compatible with terminal bacterial toxaemia. Post-mortem culture of the right lung produced a growth of Bact. Friedlander. Influenza viruses $A, B$, and $C$ were not isolated.

\section{Chemical Analysis}

The tissue specimens were placed in pyrex bottles at necropsy and shortly afterwards dissected free from extraneous tissue. If available, quantities of approximately $5 \mathrm{~g}$. fresh tissue were accurately weighed. The cadmium analysis was carried out by the dithizone procedure of Smith, Kench, and Lane (1955) which was found to be applicable to tissue, but more citrate $(4 \mathrm{~g}$.) was added to the acid digest before analysis as a precautionary measure. This was insufficient to prevent the formation of a heavy white precipitate of calcium phosphate on neutralization of the bone digests. One-tenth samples of the bone digests were taken and $20 \mathrm{~g}$. citrate added. This greatly reduced the amount of precipitate on neutralization but it was not found possible to eliminate this effect entirely.

The results of the tissue cadmium determinations are recorded in the Table. Tissue specimens from three men of comparable age with no known exposure to cadmium were examined in the same way. Any of these tissues which exhibited abnormalities at necropsy were discarded.

\section{Comment}

As in previously reported cases of death from chronic cadmium poisoning, the salient point of attack of cadmium oxide fume was the lung parenchyma, leading ultimately to severe emphysema. Here in contrast to the case of Lane and Campbell (1954) there was no sparing of the subpleural zone; the distribution of emphysema which they described does not appear to be in any way characteristic of the poison.

Lane and Campbell stressed the absence of clinical and histological evidence of chronic bronchitis in their cases. A similar absence is noted in the necropsy case reported by Bonnell (1955). In the present case, too, there is no clinical history of a chronic cough and no histological evidence of chronic bronchitis. The presence of severe emphysema without chronic bronchitis seems to be one of the characteristic features in the earlier stages of chronic cadmium fume poisoning.

The outstanding finding is the absence of any obvious tissue damage in any organ of the body other than the lungs, despite the accumulation of cadmium.

The highest cadmium concentrations were observed in hepatic and renal tissue. Relatively, however, the least increase in cadmium deposition in J. R. as compared with controls was in the kidney. Unlike many other trace metals cadmium had no obvious predilection for bone. No histological evidence of renal damage was found to explain the proteinuria. The mild chronic inflammatory reactions in the ureters and bladder can hardly be regarded as significant and no abnormalities were found elsewhere in the urogenital tract. 
TABLE CADMIUM CONCENTRATION IN TISSUES OF A MAN EXPOSED TO CADMIUM (J. R.) AND OF THREE MEN WITHOUT
KNOWN EXPOSURE

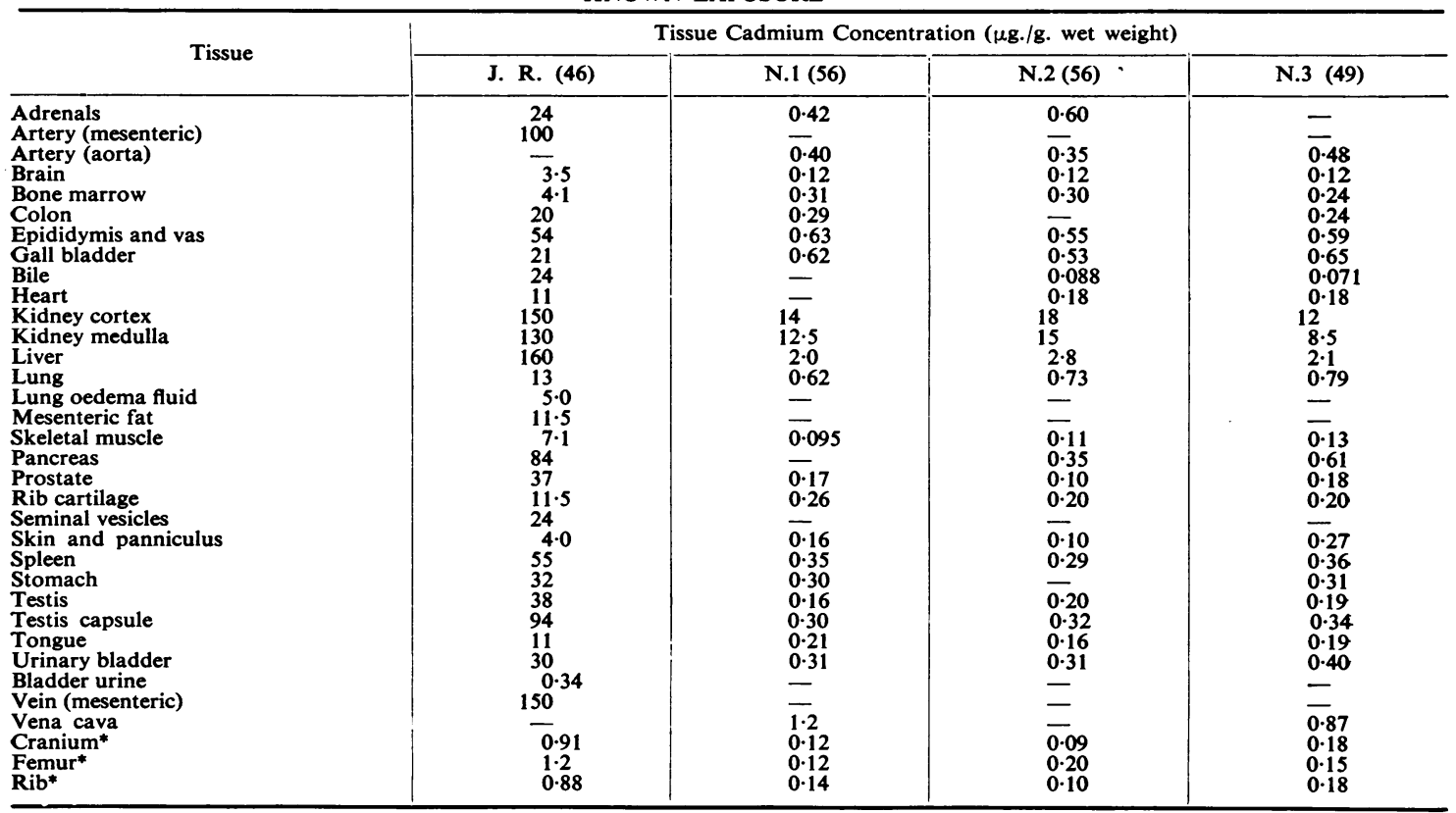

*Bone analysis unsatisfactory due to large quantities of bone mineral in acid digest.

The figures for $\mathbf{J}$. R. are in most cases the arithmetic mean of duplicate analyses.

This suggests that cadmium is absorbed from the lung as a complex which, under the conditions prevalent in the tissues, is practically non-ionized. But the epithelial cells of the lung alveoli are exposed to cadmium in the form of extremely minute cadmium oxide particles. These are likely to liberate ionic cadmium which could damage and cause rupture of the alveolar walls. Repeated episodes over many years would eventually lead to the formation of emphysematous cavities.

Early removal from exposure might retard the further development of emphysema, but if at any time a chronic bronchitis were secondarily added, the emphysema would progress. In the present case, after removal from exposure, the man lived for five years with no clinical worsening of respiratory function and at necropsy no chronic bronchitis was found.

The normal biliary cadmium concentration of men aged about 50 years is of the order of $0.080 \mu \mathrm{g} . / \mathrm{g}$. (Table). Assuming a total daily secretion of bile of $800 \mathrm{ml}$. some $64 \mu \mathrm{g}$. cadmium would be passed into the gut daily. The normal urinary cadmium excretion is less than $25 \mu \mathrm{g}$. $/ 1$. If little cadmium were reabsorbed from the gut the bile would constitute a more important pathway than the urine for the elimination of body cadmium. The biliary cadmium concentration of $24 \mu \mathrm{g}$./g. in J. R., 300 times the normal, implies a loss of some $19 \mathrm{mg}$. cadmium by this route per day.

\section{Summary}

A further case of death from chronic poisoning by cadmium fume is described.

Severe emphysema without evidence of chronic bronchitis was observed throughout both lungs. This appears to be a characteristic feature of chronic cadmium fume poisoning in its early stages.

No significant histological changes could be detected in other organs in spite of generalized cadmium deposition.

The cadmium concentrations of all the tissues examined were considerably higher than in normal controls, the greatest quantities being in the liver and kidney with relatively little in bone.

Our thanks are due to Mr. C. Bolton, H. M. Coroner, for permission to investigate this case, and to $\mathrm{Mr}$. N. Mowat for the photographs. We are indebted to Messrs. Alkaline Batteries Ltd., who supported the work by a generous grant to one of us (J. C. S.).

\section{REFERENCES}

Baader, E. W. (1951). Deutsch. med. Wschr., 76, 484.

Bonnell, J. A. (1955). British Journal of Industrial Medicine, 12, 181. Friberg, L. (1950). Acta med. scand., 138, Suppl. 240.

Lane, and Nyström, A. (1952). Svenska. Läkt, 49, 2629. Medicine, 11, 118 .

Smith, J. C., and Kench, J. E. (1957). Ibid., 14, 240.

- L., and Lane, R. E. (1955). Biochem. J., 61, 698. 